\title{
SEISMIC STABILITY OF CAISSON TYPE BREAKWATER
}

\author{
Y.Yuksel $^{1}$, Z.T.Yuksel ${ }^{2}$, B. Aydogan ${ }^{1}$, E. Cevik ${ }^{1}$ and B. Kurtulus ${ }^{1}$
}

\begin{abstract}
In recent two decades, more and more marine structures, such as breakwater, bridge, oil platform and turbines are constructed on seabed in offshore area. The stability of these marine structures after construction under the environmental loading is the main concern for the coastal engineers involved in the design work. Generally, there are two types of environmental loading in offshore area. One of them is the ocean wave and the other is the possible earthquake. Ocean wave is the conventional loading for all marine structures. However, little attention and investigation has been paid for the second type of environmental loading-seismic wave and conducted in the previous literatures. In this study, an experimental study was carried out for the stability of caisson type breakwater located on a firm bed condition under regular harmonic seismic wave. The results obtained from this experimental study were also used for the verification of the newly modified sliding block analysis model.
\end{abstract}

Keywords: caisson type breakwater; shaking tank; Newmark sliding method

\section{INTRODUCTION}

When designing a breakwater, which is one of the major facilities of the ports, the principal concern is its stability against waves, and its stability against earthquake is often neglected (OCDI, 1999). However, caisson is used not only as breakwater or waterfront structure but it is also used as an offshore bridge or oil platform for their submerged foundations (see Fig. 1).

In contrast to quay walls where loads directed toward the sea are dominant due to the action of earth pressure, with a breakwater there is no dominant loading action in a particular direction because the direction of loading action caused by inertial forces changes (Ozaki and Nagao, 2004).

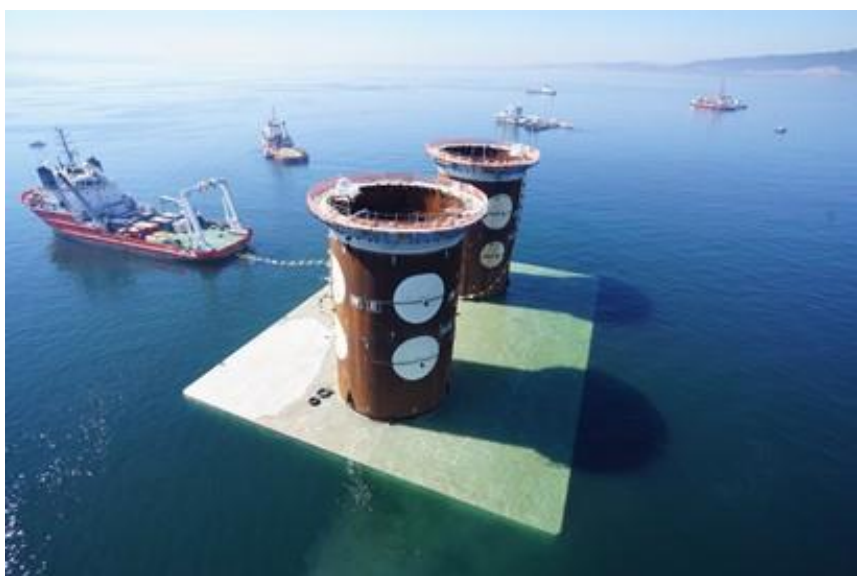

Figure 1. Floating of a caisson for submerged foundation of Korfez Suspended Bridge in Turkey.

The seismic loading is not a conventional loading for marine structures; and the strong earthquake may not occur at the zone nearby the foundation site of these kinds of structures in its usage life. However, once the earthquake occurs at nearby place, the damage to these marine structures would be devastating. For example, the failure of marine structures in Los Angeles (USA) in 1994, Kobe (Japan) in 1995, Kocaeli (Turkey) in 1999, Athens (Greece) in1999, Sumatra (Indonesia) in 2003 and Tohoku (Japan) in 2011. Some literatures are available about the earthquake induced failure of marine structures (Yuksel et al., 2002, Memos et al., 2003, Yuksel et al., 2005, Sumer et al., 2007). Therefore, besides the wave loading, the seismic loading should be considered for some important marine structures built in seismic zone.

The performance of the structure such as caisson under every state of damage must be clearly defined. Each level of design earthquake motion will be matched to its corresponding acceptable level of structural damage. However, only few literatures are available to define the responses of caisson type breakwaters under seismic wave.

1 Coastal \& Harbor Engineering, Yildiz Technical University, Davutpasa Campus, Esenler, 34220, Turkey
2 Project Company, MAG Engineering Services, Tugay Yolu Street (Ofisim Istanbul Plaza), Istanbul, 34865, Turkey 
In this study, an experimental study was carried out for the stability of caisson breakwater which is located on the firm bed condition under regular harmonic seismic wave. And also, modified sliding block model was developed to examine the experimental results.

\section{EXPERIMENTAL STUDY}

The experimental study was conducted in a shaking tank at Hydraulic and Coastal Engineering Laboratory, Yildiz Technical University. The shaking tank has $4.5 \mathrm{~m}$ length, $1 \mathrm{~m}$ width and $1 \mathrm{~m}$ height (Fig. 2).

Accelerometers, water pressure transducers and displacement transducers were used to obtain performance of the caisson type breakwater model (Fig. 3).

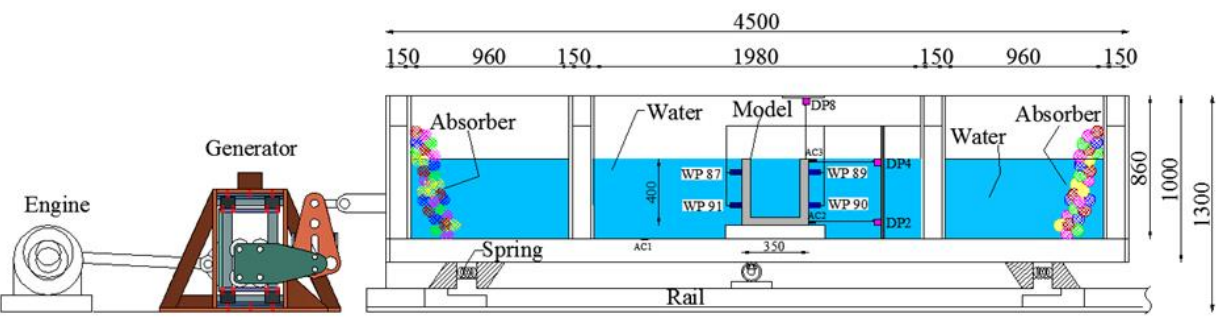

Figure 2. The cross section of the experimental set-up.

In this study, one-dimensional shaking responses were measured of caisson breakwater model because breakwaters are very long structures and seismic behavior is mainly two-dimensional. The caisson breakwater was simulated by a model with a prototype ratio of 1/10 according to Iai (1989). The simulation of various parameters was in $1 \mathrm{~g}$ gravitational field (Table 1).

It can be seen in Figures 2 and 4, the base acceleration was measured by AC1 mounted on the tank base, AC2 and AC3 correspond to the acceleration of bottom and top of the caisson, respectively. There were four water pressure transducers placed in left (WP 87 and WP 91) and right (WP 89 and WP 90) side of the caisson model to observe the water pressure variation of both sides of the model. The caisson breakwater was placed on the rigid bed. The height and width of the caisson were $40 \mathrm{~cm}$ and 35 $\mathrm{cm}$ respectively (Fig. 4). The tests were carried out under different sinusoidal harmonic loads by using $1 \mathrm{~g}$ model rule. The subjected frequency ranges were $3 \mathrm{~Hz}, 4 \mathrm{~Hz}, 5 \mathrm{~Hz}, 7 \mathrm{~Hz}$ and $8 \mathrm{~Hz}$. The test conditions were summarized in Table 2 where $\mathrm{a}_{\mathrm{bg}}$ is the base acceleration which is measured by AC1.

Figure 3. Model set-up

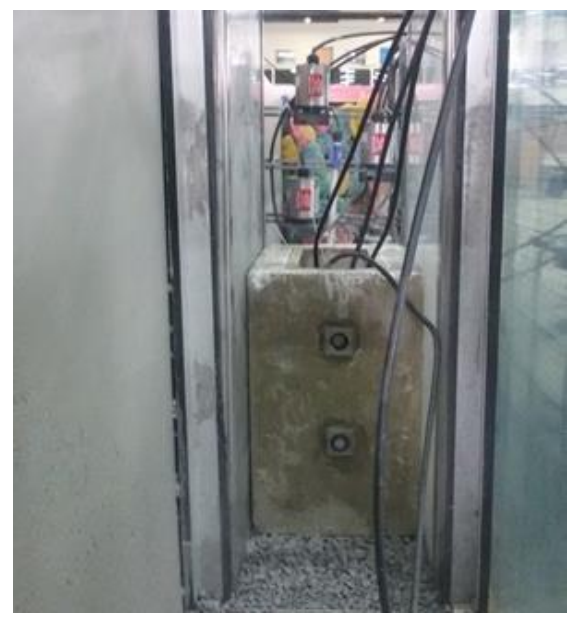




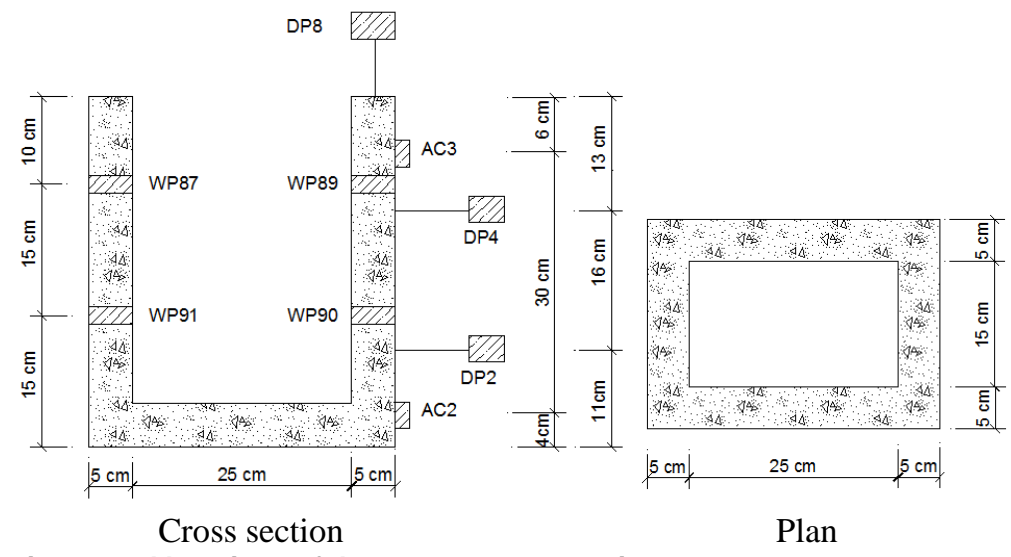

Figure 4 Model caisson and locations of the measurement equipments

\begin{tabular}{|l|c|c|}
\hline \multicolumn{3}{|c|}{ Table 1. Similitude for the $\mathbf{1} \mathbf{g}$ field } \\
\hline \multicolumn{1}{|c|}{ Parameters } & Prototype/Model & Scale factor \\
\hline Length & $\lambda$ & 10 \\
\hline Time & $\lambda^{0.75}$ & 5.62 \\
\hline Acceleration & 1 & 1 \\
\hline Displacement & $\lambda^{1.5}$ & 31.62 \\
\hline Water Pressure & $\lambda$ & 10 \\
\hline Density & 1 & 1 \\
\hline Stress & $\lambda$ & 10 \\
\hline
\end{tabular}

\begin{tabular}{|c|c|c|}
\hline Test no & $f(\mathrm{~Hz})$ & $a_{b g}(g)$ \\
\hline 1 & 3 & 0.06 \\
\hline 2 & 4 & 0.17 \\
\hline 3 & 5 & 0.40 \\
\hline 4 & 5 & 0.27 \\
\hline 5 & 8 & 0.16 \\
\hline 6 & 7 & 0.90 \\
\hline
\end{tabular}

Water pressure and its phase relation with the acceleration of caisson and displacements were evaluated. When considering the phase relation between the acceleration of the caisson and fluctuating component of water pressures, it is observed that the dynamic water pressures measured from WP91 and WP87 behave in phase with the base acceleration, while they were out of phase with the accelerations of the caisson (AC2 and AC3) (see Fig. 5 a).

On the other hand, the dynamic water pressure measured from WP90 and WP89 behave in phase with the accelerations of the caisson ( $\mathrm{AC} 2$ and $\mathrm{AC} 3)$. All the phase relations mentioned above were illustrated in Fig. 5 (b). 

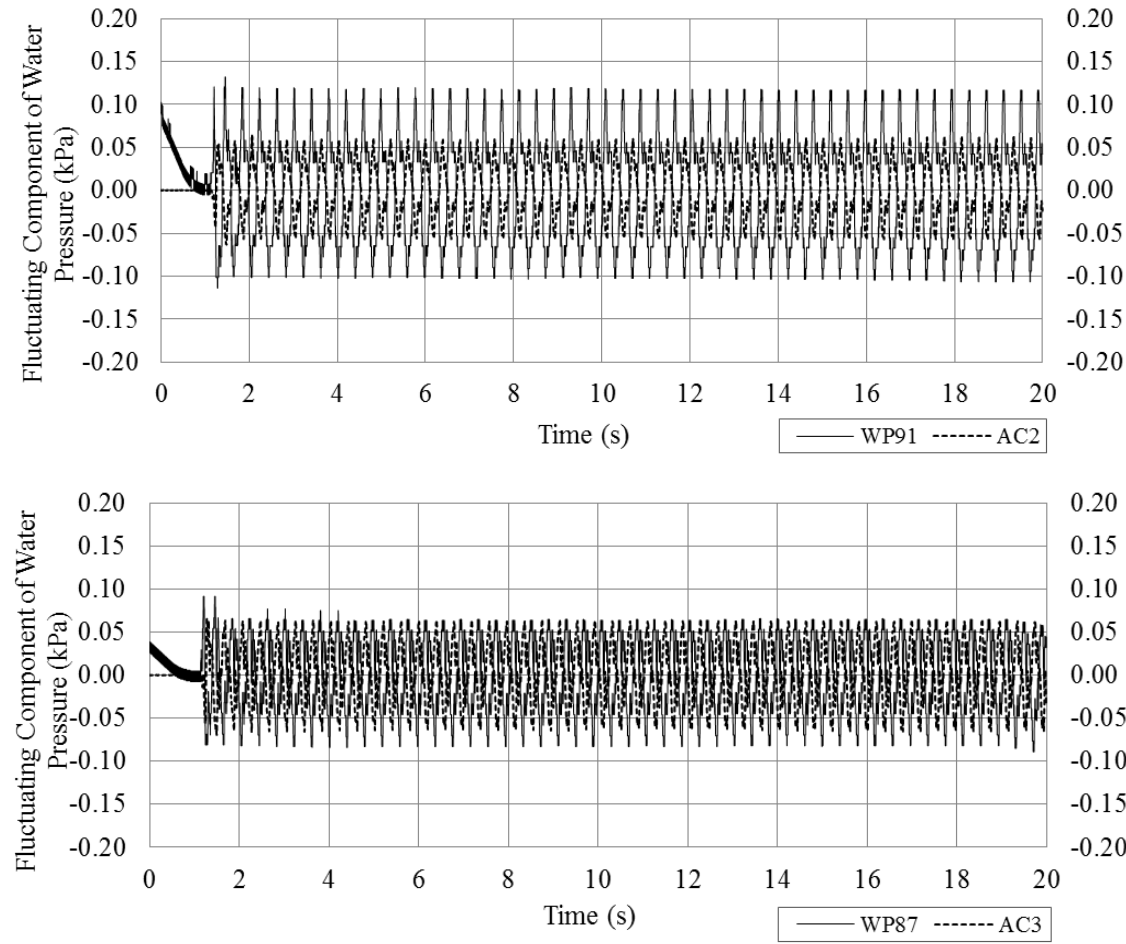

(a) Out of phase histories for left side of the caisson
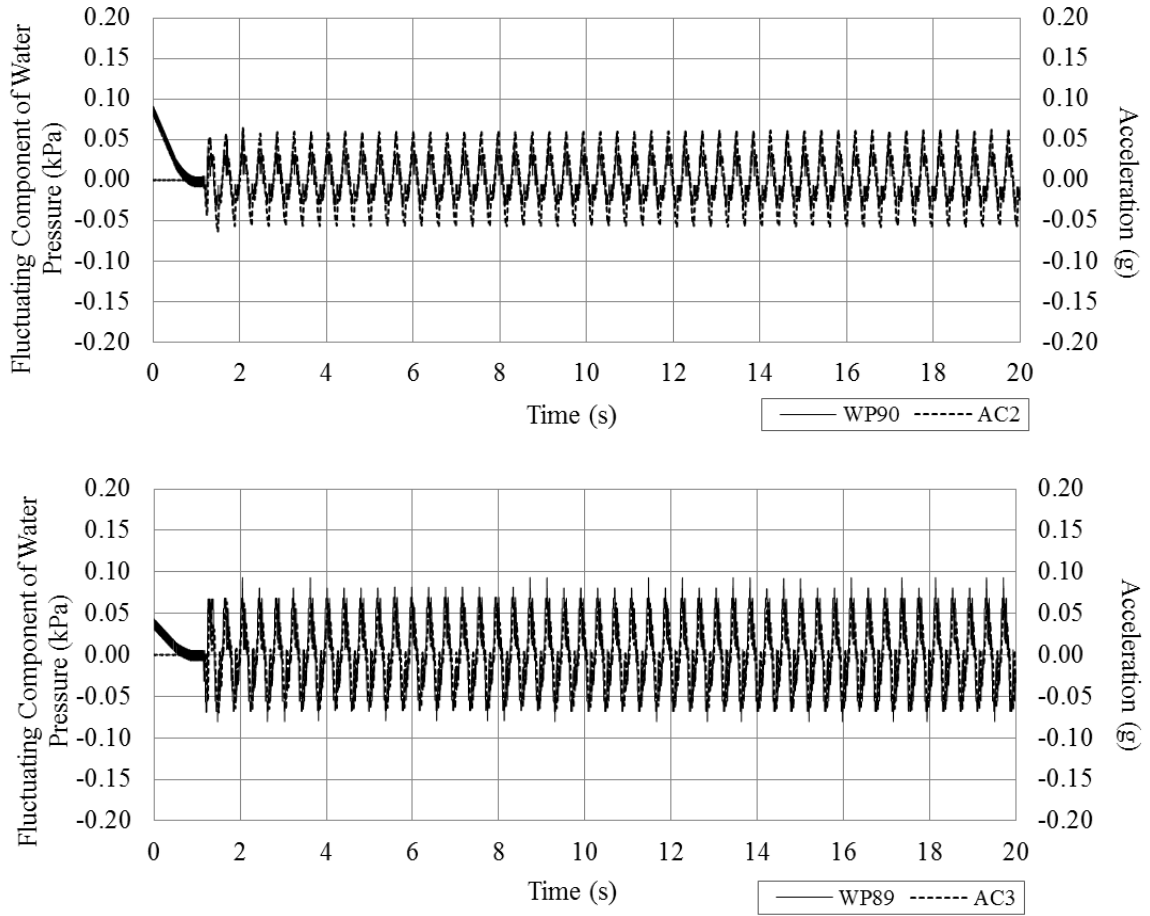

(b) In - phase histories for right side of the caisson

Figure 5 Phase relations between "the acceleration and fluctuating component of water pressure" for test 1.

The forces acting on the model were schematized in Fig. 6. It can be understood that when the tank was accelerated, the model moved to the opposite direction because of inertia force. Meanwhile, the model was accelerated together with water mass (WP90 and WP89) where the horizontal movement of the model occurred. This behavior can be concluded as added mass. However, when the caisson started to move back, the model was coincided with dynamic (fluctuating component) water pressure at nodal point of WP91 and WP87 located on the left side of the model (Fig. 2 and 5). Therefore, that part of 
water mass behaved like driving force applied on the caisson. Then, these different phase relations acted on the caisson may express how they effective on the residual displacement, especially when the friction force was overcome. In light of that outcome, it can be seen that the horizontal displacement result which subjected to " $0.17 \mathrm{~g}$ " base acceleration (test condition 4 ; the dominant frequency was 4 $\mathrm{Hz}$ ) illustrated in Fig. 7 showed a residual displacement, while caisson model showed symmetric behavior when the shaking base acceleration was smaller and no residual displacement was observed. These results also agree with Mohajeri (2004).

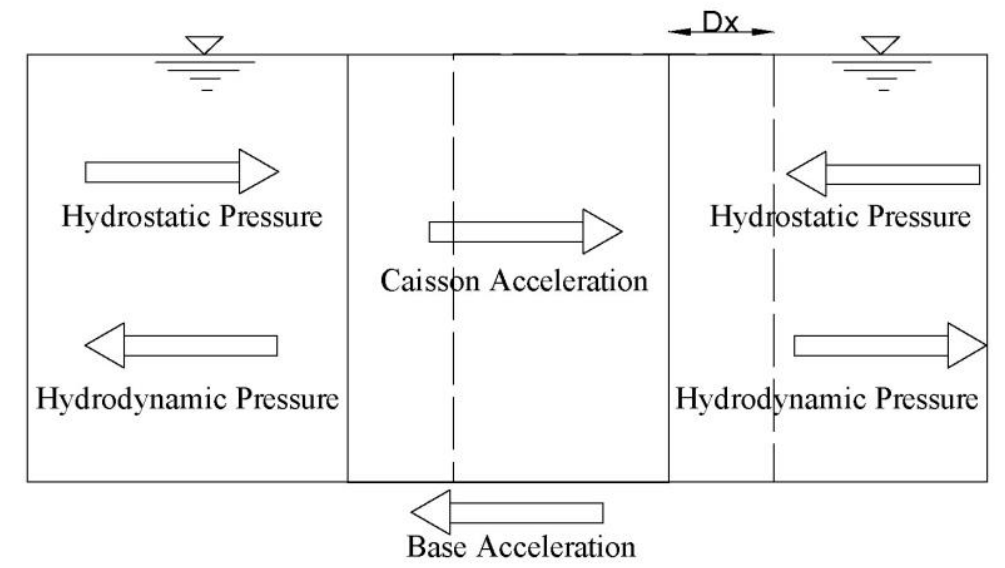

Figure 6 The schematic view of the related forces acting on the model

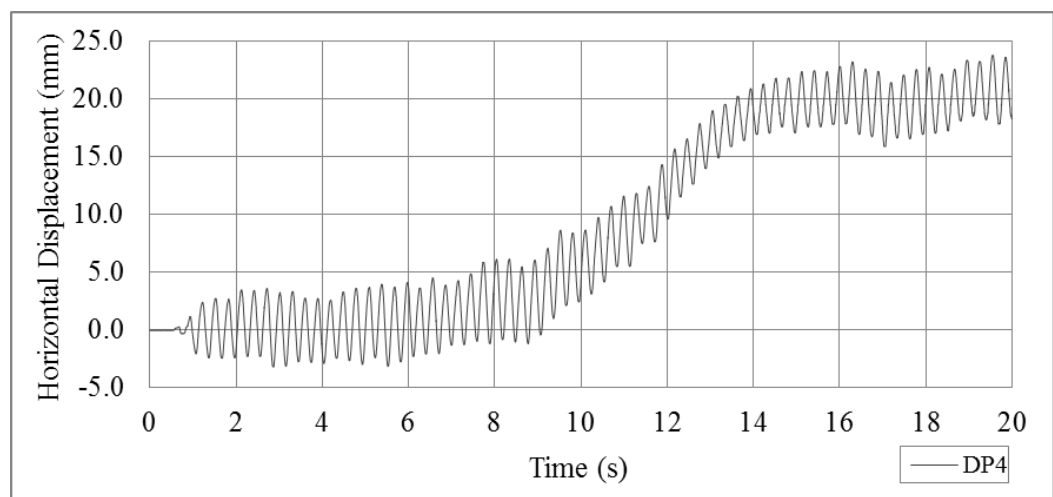

Figure 7 Horizontal displacement time history of test $4(\mathrm{f}=4 \mathrm{~Hz}$, abg=0.17g)

\section{SLIDING BLOCK ANALYSIS FOR A CAISSON BREAKWATER}

Newmark's sliding block analysis was conducted for a caisson breakwater (Elms, 2000). A caisson structure with a mass $\mathrm{m}$, is placed inside water on flat bed. A ground acceleration of $\mathrm{a}_{\mathrm{bg}} \mathrm{g}$ is applied to the system, acceleration of the caisson is ag.g, the friction between the bed and the caisson is $\mu$ 'mg, the hydrodynamic pressure acting on the caisson is Pmg. W is the weight of the submerged caisson and the $\mu^{\prime}=\mu \mathrm{W} /(\mathrm{mg}$ ) where $\mu$ is the friction coefficient (Fig. 8).

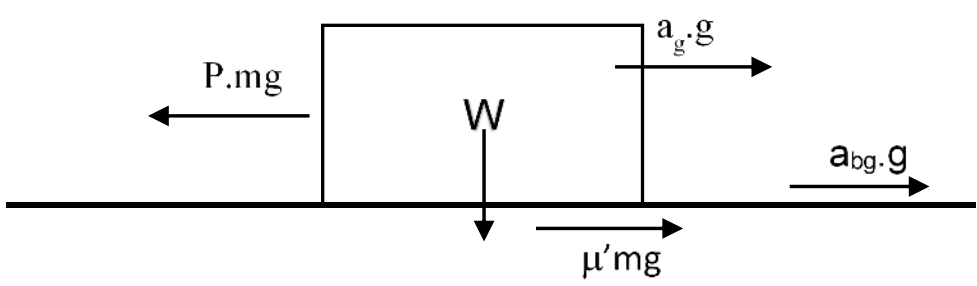

Figure 8 Sliding block concept 
The yield acceleration is calculated by Equation 1, depending on the direction of the ground acceleration.

$$
a_{g Y}^{+}=-P+\mu^{\prime} \quad a_{g Y}^{-}=-P-\mu^{\prime}
$$

Acceleration of the caisson is calculated by Equation 2. $\mathrm{V}$ is the relative velocity of the caisson.

$$
a_{g}=-\frac{V}{|V|} \mu^{\prime}-P
$$

While the caisson is moving together with the ground, (relative velocity is 0 ) the first term may be substituted with the following term for the calculation of the caissons acceleration.

$$
\frac{\mathrm{V}}{|\mathrm{V}|}=\frac{-\left(\mathrm{a}_{\mathrm{bg}}+\mathrm{P}\right)}{\left|\mathrm{a}_{\mathrm{bg}}+\mathrm{P}\right|}
$$

Relative acceleration velocity and the displacement may be calculated by Equations 4,5,6.

$$
\begin{gathered}
\mathrm{a}=\left(\mathrm{a}_{\mathrm{g}}-\mathrm{a}_{\mathrm{bg}}\right) \mathrm{g} \\
\mathrm{V}=\mathrm{V}_{0}+\int \mathrm{adt} \\
\mathrm{s}=\mathrm{s}_{0}+\int \mathrm{Vdt}
\end{gathered}
$$

Hydrodynamic pressure forces acting on each side of the caisson structure were calculated by vertically integrated Westergaard formulation as given in Equation 7.

$$
\mathrm{F}_{\mathrm{HD}}=\frac{7}{12} \mathrm{a}_{\mathrm{g}} \times \gamma \times \mathrm{H}^{2}
$$

Model description was given in Fig. 9. First the hydrodynamic force, minimum velocity and yield accelerations are computed. Minimum velocity is the velocity that may be decelerated to 0 within one time step due to friction.

Then if the ground acceleration is less than the yield acceleration and the current relative velocity is less than minimum velocity than the caisson will have no relative velocity (it will move with the bed), and the caissons' acceleration will be equal to the bed acceleration. If the bed acceleration is greater than the yield acceleration (in absolute manner), the relative motion will occur with the caisson and the bed. Once the relative motion starts the friction will try to stop the relative motion and will always be in the opposite direction of the relative motion. So, the caisson will have a different acceleration than the bed which will require a recalculation of the pressure force. An iterative approach has been adopted to compute the $\mathrm{P}$ and $\mathrm{a}_{\mathrm{g}}$ as they are both function of each other. First $\mathrm{a}_{\mathrm{g}}$ is calculated and then pressure force is obtained from $\mathrm{a}_{\mathrm{g}}$ and this pressure is then used in calculation of a new $\mathrm{ag}_{\mathrm{g}}$. This iteration was repeated 10 times. Static and dynamic friction coefficients were used as calibration factors in this model. 


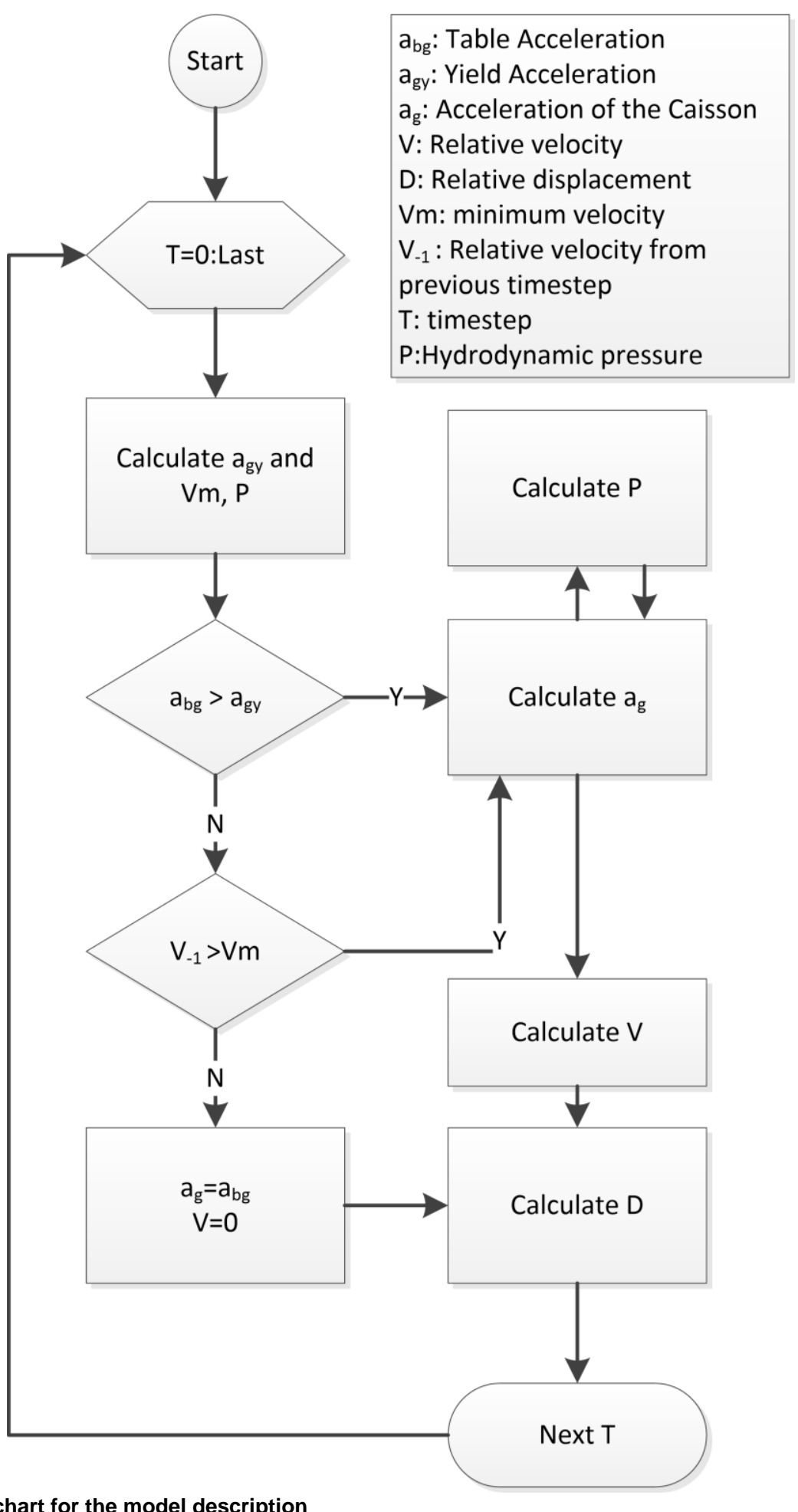

Figure 9 Flow chart for the model description

Figure 10 and 11 showed that the additional lateral excitation caused increasing of the caisson displacement and the results were found agree with the experimental results for test 2 and 3 respectively. 


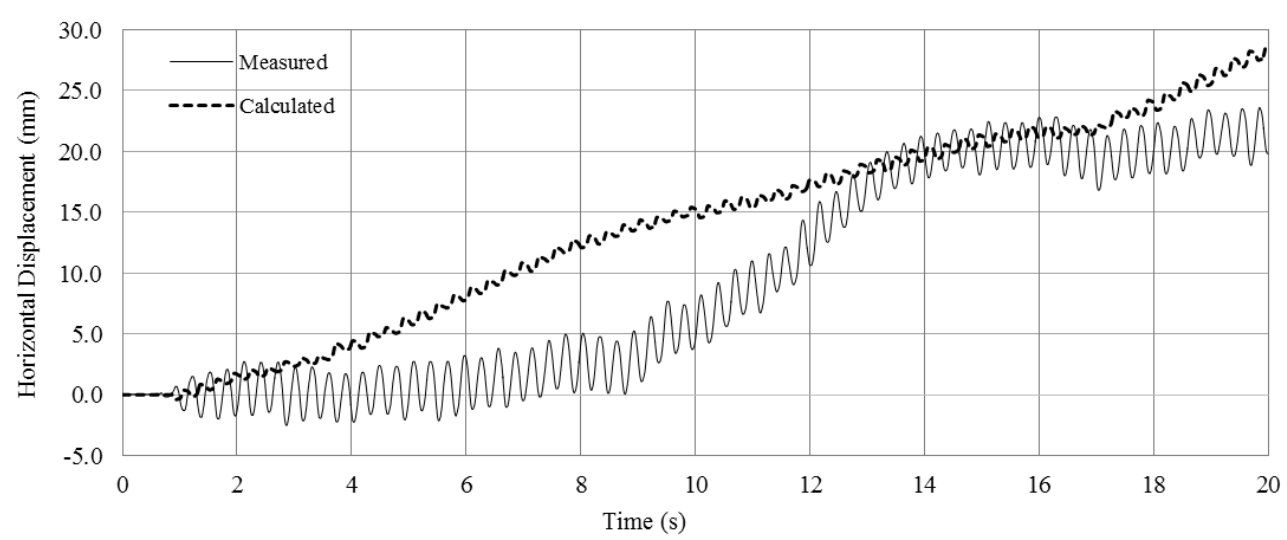

Figure 10 Horizontal displacement time history for both test 2 and the modified sliding block analysis model.

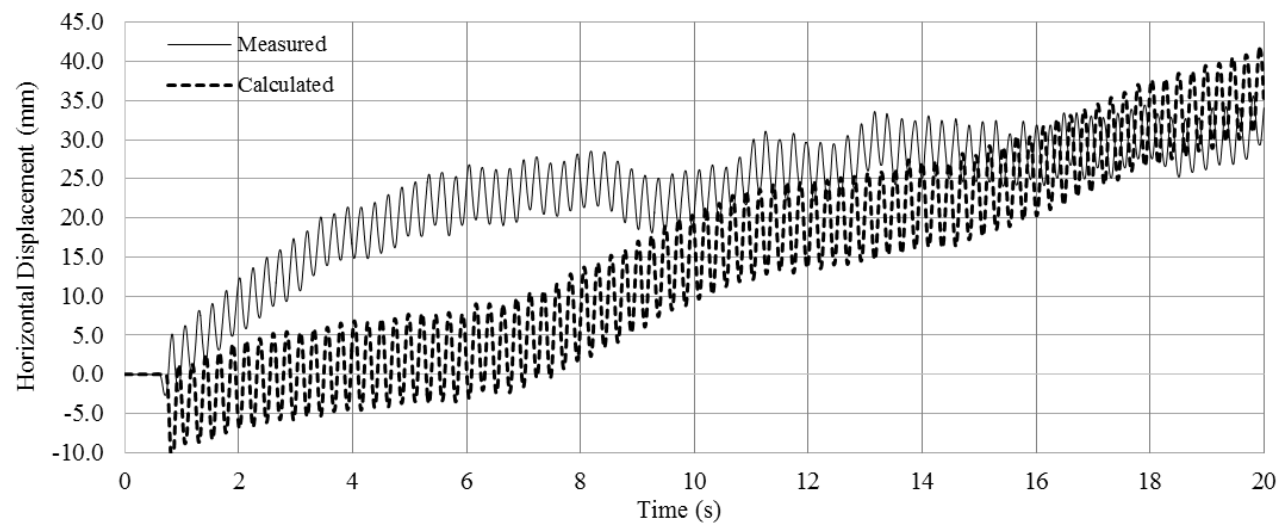

Figure 11 Horizontal displacement time history for both test 3 and the modified sliding block analysis model.

\section{CONCLUSION}

This study shows the performance of the caisson type breakwater exposed to seismic loading. The conclusions are summarized as follows.

1. Experiments were carried out by using six different regular harmonic seismic shaking with $1 \mathrm{~g}$ method. Tests had different shaking frequencies and amplitudes. Observations showed that a residual displacement occurred under strong shaking due to caisson inertia and added water mass.

2. Modified sliding block analysis model showed that the yield acceleration at the time that sliding tended to start and during the sliding was not a constant value and it seemed that the yield acceleration decreased immediately after sliding.

\section{ACKNOWLEDGMENT}

The authors wish to express their sincere appreciation to TUBITAK for funding for research project no 113M426.

\section{REFERENCES}

Elms, D.G. 2000. Refinements to the Newmark Sliding Block Model, 12WCEE.

Iai, S. 1989. Similitude for Shaking Table Tests on Soil-Structure-Fluid in 1g Gravitational Field, Soils and Foundations, 29 (1), 105-118.

Memos, C., Kiara, A. and Pavlidis, E. 2003. Coupled Seismic Response Analysis of Rubble-Mound Breakwater, Water and Maritime Engineering, ICE, 23-31.

Mohajeri, M., Ichii, K., Tamura, T. 2004. Experimental Study on Sliding Block Concept for Caisson Walls, Journal of Waterway, Port, Coastal and Ocean Engineering, ASCE, 134-142.

OCDI 1999 Technical Standards and Commentaries for Port and Harbour Facilities in Japan 
Nagao, T., and Ozaki, R. 2004. Earthquake-Resistant Design of Caisson Breakwaters, Proceedings of Structural Engineering, JSCE, 50A, 217-228.

Sumer, M., Ansal, A., Cetin, K.O., Damgaard, J., Gunbak, A.R., Hansen, N. E. O., Sawicki, A., Synolakis, C.E:, Yalciner, A.C., Yuksel, Y., and Zen, K. 2007. Earthquake-Induced Liquefaction around Marine Structures, Journal of Waterway, Port, Coastal and Ocean Eng., ASCE, 133/1, 5582.

Yuksel, Y., Alpar, B., Yalciner, A.C., Cevik, E., Ozguven, O., Celikoglu, Y. 2002. Effects of the Marmara Earthquake on the Marine Structures and Coastal Areas, Journal of Water and Maritime Engr., ICE, 156, 147-163.

Yuksel,Y., Ozguven, O., Cetin, O., Işik, S., N., Cevik, E., Sumer, M. 2005. Seismic Response of Ereğli Fishery port Rubble Mound Breakwater, Maritime Engineering Journal, ICE, 157/MA4, 151-161. 